\title{
密充塡に近い高濃度セラミックス・サスペンションの レオロジー挙動
}

\author{
中丸 八 郎*, 俵 弥 寿 至**, 長 瀬 洋 一*
}

\section{Rheological Behavior of Highly Filled Ceramic Suspensions}

by

Hachiro NAKAMARU ${ }^{\dagger}$, Yasushi TAWARA ${ }^{\dagger \dagger}$ and Yoichi NAGASE ${ }^{\dagger}$

\begin{abstract}
Viscoelastic properties of highly filled suspensions (HFS) of ceramic powders-bentonite, kaolin, alumina and titania-mixed with various binders were tested by means of the mono-axial compression method. The rheological properties of HFS before and at rupture were : Strains at rupture, $\varepsilon_{\mathrm{R}}$, were independent of concentration and were in the range, 0.1 to 0.2 , for every combination of powders and binders. Rupture strengths, $\sigma_{\mathrm{R}}$, were highly dependent on solid concentration and varied with powders and binder combinations. A binder, HPMC, gave adhesiveness and softness to the HFS, and did not show complete rupture. The CMC gave the most brittle nature to the HFS. In addition, thixotropic hardening was observed for long time loading with every sample. Burgers' model in which the time dependency term was introduced into the Maxwell part was presented to simulate the rheological behavior of HFS. Finally, the effect of binders was quantitatively estimated.
\end{abstract}

Key Words : Highly Filled Suspension, Ceramics, Binders, Rheological Behavior, Rheological Model

\section{1. 緒产}

セラミックスの用途拡大に伴って, 粒子相互は接触

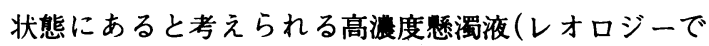
はHighly Filled Suspensionといわれる。以下はセ ラミックス粒子・水系を対象とし, HFSと略称する。) のレオロジーに関心が高まっている。その技術目的は 多様であるが, 操作としてはHFSの変形, 破壊, すべ りなどに集約できる。すべりには固体壁とのすべり とHFS内部におけるすべり破壊 ${ }^{7,8)}$ が考えられ，これ

1993年 9月 16 日 受付

* 広島大学工学部化学工学教室 (T724 東広島市鏡山 1-4-1) TEL. 0824-24-7717

* 三洋化成工業 (株)（广605 京都市東山区一橋野本町 11-1） TEL. 075-951-9321

$\dagger$ Dept. of Chem. Eng., Hiroshima Univ.

(1-4-1 Kagamiyama Higashihiroshima City 724)

t† Sanyo Kasei Kogyo Co., Ltd.

(11-1 Nomotocho, Ichino-hashi, Higashiyamaku, Kyoto 605)
らに関する研究は継続的に行われてきた。著者らの考 察は別に報告している ${ }^{9,10)}$ 。一方HFSの変形や破壊举 動については土質工学において ${ }^{11 \sim 14)}$, 一軸叉は三軸圧 縮試験にもとずく考察が多くなされている。著者らも 一軸圧縮試験法によって, HFSが破壊限界以内の微小 ひずみ範囲内で, ひずみ硬化やチキントロピーなどが 現れることを報告した ${ }^{15)}$ 。実用的にはHFSの脆性等を 改善するために各種の添加剂(結合剂, 可塑剂, 潤滑剂 等)が混入される。本報では結合剂のみをHFSに混練 したときのHFSのレオロジ一的変化, 結合剤の有無に 関せずHFSに共通するとみられるレオロジ一挙動な どを報告する。次に結合剤によるHFSの改善効果を定 量的に評価することを目的にして,レオロジ一性質を なるべく簡潔に表現できるモデルを導入する。

本報の对象はセラミックス粒子・水系としたが, 得 られた結果は粒子・有機バインダ一系などHFS一般 に共通するところが多いと推察される。 


\section{2. 試料及び試験法}

HFSに对する各種添加剂量は目的に応じて調整され るが,ここでは結合剤のみを用いることにする。実験 したサンプルと結合剤の種類をTable 1に示した。

カオリン(ジョージア)は水と共に十分混練した試料 及び水と混練する際に結合骫としてヒドロキシプロ ピルメチルセルローズ(HPMC. 信越化学製メトース 90SH3000平均分子量65万), カルボシキメチルセルロ 一スNa塩 (CMC. 林純薬工業製), ポリビニルアルコ 一ル(PVA. 和光純薬工業製 平均分子量 6.6万), ヒド ロキシプロピルセルロース(HPC．日本曹達製 $\mathrm{HPC}-\mathrm{H}$ 平均分子量 25 40万), 及びポリビニルメチ ルエーテル(PVM. 東京化成工業製)をそれぞれ固体 に対して $5 \%$ 添加してロールによって混練した。ロー ル間隙を幾度も通して十分に混練した試料を，直径 $15 \mathrm{~mm}$ ，高さ $30 \mathrm{~mm}$ の円柱に成形して24時間以上放置 し(以下の試料も同じ) 一軸圧縮試験を行った。アルミ ナ, 酸化チタンは水と混練するだけでは成形体にでき ないので, 上記の結合郕を固体に対して $5 \%$ 添加混練し たもののみを成形した。一方ベントナイトは水と混練 するだけで十分な成形体となる。水のみ及び添加剤混 合のいずれの場合も，固体の水と固体との和に对する 重量割合(以下固体湌度 $C$ はこの意味とする)の上・下 限は本実験で用いた混練機によって混練可能で，かつ 自重によって変形しない範囲に限られ，試料及び結合 剂毎におのずから決まる。試験した䈨度範囲をTable 1に示した。

試験装置は前報 ${ }^{15)}$ と同様にFig. 1に示す一軸圧縮試 験法によった。HFSの破裹試験は三軸圧縮法がよいと されている ${ }^{16)}$ 。しかし，この方法によると破壊点は正 確に求まるが, 破壊までの変形状態や表面の観察が出 来にくいので(Figs. 4 及び 5 参照)，側面拘束のない一 軸圧縮試験を採用した。試料の上下面にテフロン薄板 をおき，電子天科上で，上より分銅また油圧ピストン によって負荷を加えた。テフロン板を介することに

Table 1 Experimental range of concentration, $C$, of HFS (wt \%) with and without binder.

\begin{tabular}{lcccc}
\hline & Bentonite & Kaolin & Alumina & Titania \\
\hline Without binder & $20-35$ & $65-75$ & - & - \\
HPMC & - & $65-75$ & $76-86$ & $68-78$ \\
PVA & - & $68-75$ & $80-86$ & $72-78$ \\
CMC & - & $60-70$ & $75-85$ & $65-75$ \\
HPC & - & - & $80-86$ & $72-78$ \\
PVM & - & $70-75$ & - & -
\end{tabular}



Fig. 1 Apparatus for uniaxial compression test

よって板とHFSとの摩撩は隇少し，ゆっくり圧縮する ときはほぼ円柱状を保ったままで変形する。試験は破 噮強度以下の応力でクリープ, 繰り返しクリープ及び 定速度ひずみ増加を主として行い, 荷重のステップ状 增加や応力楥和も適時行った。定速度ひずみ増加は破 壊*1を確認するためである。以下は初期試料断面積及 び初期試料円柱長さを基準にした応力 $\sigma$ 及びひずみ $\varepsilon$ とした。

\section{HFSのレオロジー慨要}

前報15)ではクリープ試験において粘弾性を示し，か つ残留ひずみがあること，ひずみ硬化を示すこと，例 えば応力を一定にして載荷と除荷とを繰り返すと(繰 ク返しクリープ), Figs. 2及び3のように瞬間ひずみ 応答, 残留ひずみは繰り返し回数と共に減少していく, すなわち硬化することを明らかにした。また試験終了 後一昼夜程度放置しておくと，ほぼ元の状態にまで回 復(軟化)し, 全体として(逆)チキントロピー性*2を示 すことを指摘した。このことは今回試験したすべての 試料にみられた。Figs. 2および3はその一例で, Fig. 2はベントナイト・水系の, Fig. 3はHPMC添加酸化 チタン・水系の繰り返しクリープ例である。クリー プ回数と共に瞬間ひずみ応答及び残留ひずみの増加割 合が小さくなる非線形的な時間依存固化が起こってい る。このことは今迄明確にされていなかったことで あるので, 本報では多種類の試料について検討し, こ れらの現象が大なり小なりHFSに共通することを確 認した。

結合剂の効果について次のことがわかった HPMC はHFSの脆性を改善する良好な添加剂であるといわ れている17)。Figs. 4および5は無添加カオリン・水系

*1 前報 ${ }^{15)}$ では破壊を降状とみなした。本報ではHFSに関する通例 にならって破瞔とよぶことにする。

*2 応力によって軟化し, 応力を除くと元の状態に回復する場合を通 常(正)チキソトロピーといわれる。 


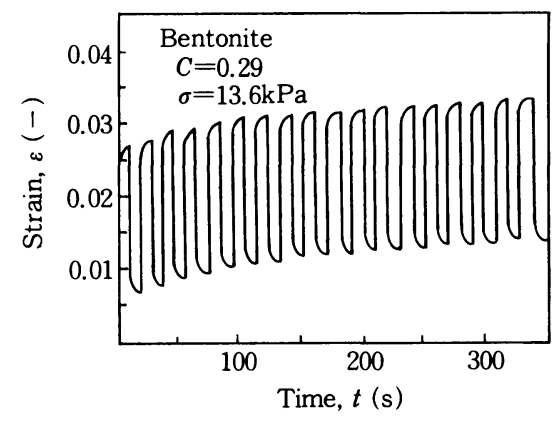

Fig. 2 Repeated creep test of bentonite-water HFS



Fig. 3 Repeated creep test of titania-HPMC-water HFS

とHPMC添加カオリン・水系のHFSについて, 定速 度ひずみ増加試験結果と,ビデオによって変形状態を 外部から観察した結果とをまとめて示したものであ る。応力応答のみをみると, ひずみ $\varepsilon$ が小さい範囲では 無添加もHPMC添加も大差なく, 粘弾性的な応答を示 している。しかし破壊挙動は全く違う。図上に, 円柱 表面にクラックが入り，これが発達する様子を付記し ているが, Fig. 4にみられるように, 無添加の時は脆 性材料に共通した特徵，すなわち始めに小さなクラッ クが現れ，やがて 1 または 2 箇所のクラックが急速に 発達して破壊に至る。これに対してHPMC添加のと きは(Fig. 5)，表面にクラックが現れ始めると,これ を覆い込むように局所流れが起こり，クラックを修復 するが, 同時に表面にくびれが残る。こうしてくびれ が多く発生するようになるが破断に至ることはなく， 全体として半径が大きくなっていく。したがって Fig. 4のような破壊後の応力減少がない。HPMCは試 験したすべてのセラミックスについて大なり小なり 上記のような脆性改善機能がみられ，良好な結合剤で あった。これに对してCMCを添加すると，いずれの HFS 硬くはなるが脆性は改善しない。PVAは HPMC と同様に脆性は改善するが, 全体に軟らかくな り, 保形性が弱まる。PVMとHPCはCMCとPVAの

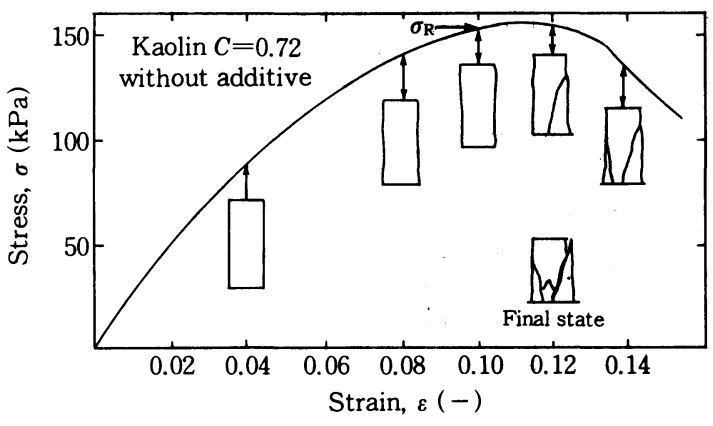

Fig. 4 Stress response of increasing strain test (solid line) and visual deformation of kaolin-water HFS

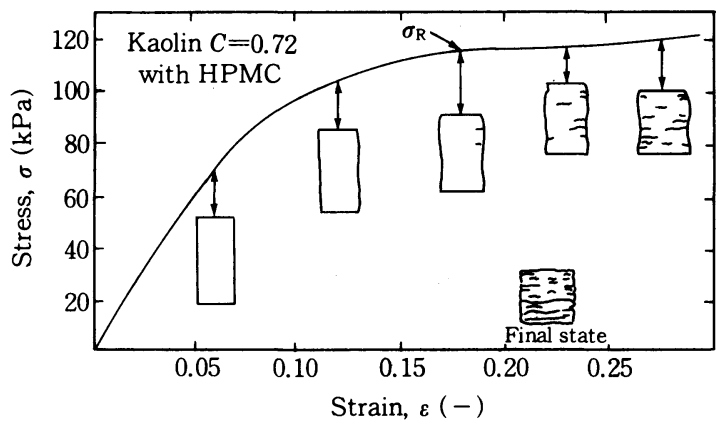

Fig. 5 Stress response of increasing strain test (solid line) and visual deformation of kaokin-HPMCwater HFS

中間的な性質を与えた。これらの特徴はレオロジ一的 に定量化しにくいけれども，使用したすべてのセラミ ックスについても大なり小なり共通する結合剤の重要 な作用であると考えられる。

結局HPMCのみが良好な結合剂であることがわか ったが，このことを別置すると，結合剤の種類に関せ ずすべての試料にみられた大きな特徵は破壊限界ひず みと破壊応力にあった。便宜的ではあるが, 円柱表面 に最初のクラックまたはくびれを生じ始めたときの 応力とひずみをそれぞれ破壊応力 $\sigma_{\mathrm{R}}$, 破壊限界ひずみ $\varepsilon_{\mathrm{R}}$ と定義すると, $\varepsilon_{\mathrm{R}}$ は固体㴤度によらずほぼ一定であ つた。また結合剤の種類, 固体の種類にもよらず, Fig. 6に例示したように大約 $\varepsilon_{R} \doteqdot 0.1 \sim 0.2$ の範囲に限 られることであった。例えばカオリン・水・添加剂系 の場合は, HPMC添加が $\varepsilon_{R} \doteqdot 0.18$ で大きく, PVA, PVM, CMC添加の場合は $\varepsilon_{\mathrm{R}} \doteqdot 0.1 \sim 0.15$ 範囲にあ る。一方 $\sigma_{\mathrm{R}}$ はFig. 7に例示したように粒子及び結合剂 の種類によって大幅な相違があり，また漕度依存性が 大きい。カオリンについてはHPMC添加の場合を除 いて， $\varepsilon_{R}$ はほとんど差がないにもかかわらず， $\sigma_{R}$ は 




Symbols : $\bigcirc, \square, \diamond$ HPMC ; $\ominus$ PVM ; 日, $\ominus, \mathrm{HPC} ; \oplus, \mathbb{}, \bowtie$ PVA ; $\oplus, \boxplus, \oplus \mathrm{CMC}$; without binder

Fig. 6 Strain at rupture, $\varepsilon_{R}$

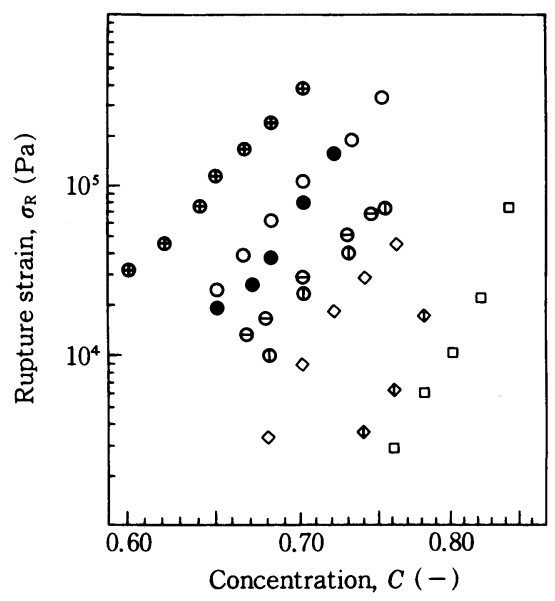

Symbols : for kaolin $\oplus$ CMC, $\bigcirc$ HPMC, $\ominus$ PVM, (1) PVA, without binder : for titania $\diamond$ HPMC, $\triangleright$ PVA ; for alumina $\square$ HPMC

Fig. 7 Dependency of rupture stress on concentration with various $\mathrm{HFS}$

CMC 添加, 無添加, PVM, PVA添加の順になってい る。一方, $\varepsilon_{\mathrm{R}}$ はHPMC添加の方が無添加のそれより大 であるにもかかわらず両者の破壊応力は差がない。

破壊に至るまでの粘弾性については土質や空業の分 野で種々のモデルが提案されているが18 21), 前報15) に 加えて本報ではクリープ, 応力䌅和, ひずみ(叉は応 力)連䋨増加試験などの各種の試験を行った。その結果 次のことが分かった。繰り返し(叉は長時間)クリープ のように破壊応力以下の一定応力のもとで長時間にわ たって試験していると, 徐々に硬化する(その程度は 試料調整後の放置時間によって変わるであろう)。こ れを除荷して長時間放置しておくと(逆)チキソトロ



Fig. 8 Modified Burgers' model

ピ一的に軟化する。クリープ，応力緩和，ひずみ(叉は 応力)増加のいずれにおいても短時間試験のときの応 力(叉はひずみ)応答はおおむね約 Maxwellモデルに 従う。ただしMaxwellモデルのみではFigs. 2及び 3 のように載荷時や除荷時の直後の滑らかな応答曲線を 表現できない。この滑らかな応答はVoigtモデルと Maxwellモデルとを直列結合すると（Burgersモデル， Fig. 8)ほぼ表現できる。したがって除荷しない連続 ひずみ(叉は応力)増加ではMaxwell モデルのみでほ ぼ近似できる。さらに連続ひずみ(叉は応力)増加では 試験時間内でひずみ硬化も起こらないとみなしてよ かった。まとめると, HFSのレオロジ一応答は Maxwellモデルが主で, Voigt要素は従的にこれを修 正する(とくに除荷のとき)。試験法について分類する と,

グループ I : 長時間クリープや応力緩和のときは Maxwell要素に時間依存硬化を付与したBurgersモデ ルで近似できる。

グループII : 連続ひずみ(叉は応力)増加のとき, 時間 依存を与えない単純な Maxwell モデルで近似でき る。

グループIIの場合のように，時間依存硬化が陽にみ られない場合があることについて, 本質的な理由は不 明である。したがって統括的なレオロジーモデルを 得るには至っていないが, Maxwell 要素が主で, Voigt 要素は従的な修正要素であることは間違いない と考えられる。定量的にも，後記するようにグループ I，II共に同一のMaxwell要素(数值)を用いることが 出来た。グループIのように, 長時間にわたってクリ 一プを続けるときは, 荷重に対抗するように粒子配列 が多少変化(粒子間のわずかな滑りや回転)するために ひずみ硬化を起こし, 応力を除くと配列変化が回復す 
る。これに对して,ひずみ(叉は応力)が常に増加して いる場合には, HFSは成形したときの粒子配列を保っ たままで変形するのではないかと考えられる*3。

\section{4. レオロジーモデル}

HFSのレオロジーの本質は複雑であろうと推察さ れる。しかしここでは結合剤のHFS改善効果をなる ベく簡潔に表現するレオロジーモデルを用いる。前節 によるとグループI が一般的な場合, グループII は HFSのレオロジ一的骨格を与えることになる。

1）一般の場合(グループI）: Maxwell要素にひず み硬化を表わす時間依存性を次のEqs. (1)及び(2)のよ うに仮定した。

$$
E_{\mathrm{M}}(t)=E_{\mathrm{M}} \cdot f(t), \eta_{\mathrm{M}}(t)=\eta_{\mathrm{M}} \cdot g(t)
$$
$f(t), g(t)$ の関数形 :

$$
\left.\begin{array}{l}
f(t)=\alpha_{\mathrm{E}}-\left(\alpha_{\mathrm{E}}-1\right) \exp \left(-\frac{t}{\theta_{\mathrm{E}}}\right) \\
g(t)=\alpha_{\eta}-\left(\alpha_{\eta}-1\right) \exp \left(-\frac{t}{\theta_{\eta}}\right)
\end{array}\right\}
$$

Eq. (1)を加味したときのBurgersモデルは

$$
\begin{aligned}
& E_{\mathrm{M}} f(t) \ddot{\varepsilon}+\frac{f(t)}{\tau_{\mathrm{V}}} \dot{\varepsilon} \\
& =\ddot{\sigma}+\left(\frac{1}{\tau_{\mathrm{M}} h(t)}+\frac{\frac{E_{\mathrm{M}} f(t)}{E_{\mathrm{V}}}+1}{\tau_{\mathrm{V}}}-2 \frac{\dot{f(t)}}{f(t)}\right) \dot{\sigma} \\
& +\left\{\frac{1}{\tau_{\vee} \tau_{M} h(t)}-\frac{\dot{f}(t)}{f(t)}+2\left(\frac{\dot{f}(t)}{f(t)}\right)^{2}\right.
\end{aligned}
$$

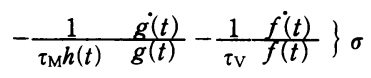

ただし, $h(t)=g(t) / f(t)$

Eq.(3)で例えばクリープのときは $\ddot{\sigma}=\dot{\sigma}=0, \sigma=-$ 定, 応力緩和のときは $\ddot{\varepsilon}=\dot{\varepsilon}=0, \varepsilon=$ 一定, などになる。

2）レオロジー的骨格(グループ II) : Voigt 要素及 び時間依存要素を無視する。単純 Maxwell要素のみに なり, Eq. (1)と同一の $E_{\mathrm{M}}, \eta_{\mathrm{M}}$ を用いるとして,

$$
\dot{\sigma}+\frac{E_{\mathrm{M}}}{\eta_{\mathrm{M}}} \sigma=E_{\mathrm{M}} \dot{\varepsilon}
$$

\section{で表わされる。}

各式中の係数值はクリープにおける載荷した時の瞬 間応答より $E_{\mathrm{M}}$ を, 載荷時間を長くして除荷した時の瞬

*3このことは各要素の時間及び周波数依存を想定させるが周波数 依存性は楥慢であると考えられるのでEqs. (1)〜 (4)で近似した。
間応答より $E_{\mathrm{M}}(t)$ を, 残留ひずみ $\varepsilon_{\mathrm{P}}=\sigma_{\mathrm{c}} t / \eta_{\mathrm{M}}(t)$ より $\eta_{\mathrm{M}}(t)$ をここれの $t \rightarrow 0$ への外插により $\eta_{\mathrm{M}}$ を, 除荷後の応 答曲線に一致するように $E_{\mathrm{V}}, \eta_{\mathrm{v}}$ を求めた。

\section{5. 添加剤の効果}

Eqs.(3) 及び(4)の係数值はカオリンにHPMC, CMC, PVA添加及び無添加の場合Fig. 9のようであ った。Eq. (2)の係数値はTable 2に示した。 $E_{\mathrm{M}}, E_{\mathrm{V}}$, $\eta_{\mathrm{M}}, \eta_{\mathrm{V}}$ の值は 4 種の試料についてほぼ 1 桁もの相違を 示している。CMC添加は 4 個の係数共に大, とくに $E_{\mathrm{M}}$ が大になっている。一方PVA添加はいずれの係数 も最も小さい。いずれも硬くなる $(\mathrm{CMC})$, 軟らかく なる(PVA)ことを定量的にとらえている。HPMC添 加は $\eta_{\mathrm{M}}, \eta_{\mathrm{V}}, E_{\mathrm{V}}$ が相対的に小で, 軟らかくなる傾向は あるが, $E_{\mathrm{M}}$ と $\varepsilon_{\mathrm{R}}$ とが大であるために, 無添加と同程度 の破壊強度を保つ(Fig. 7)ことがわかる。これらの結 果とFigs. 4及び 5 の一軸圧縮試験及び破壊状況の観察

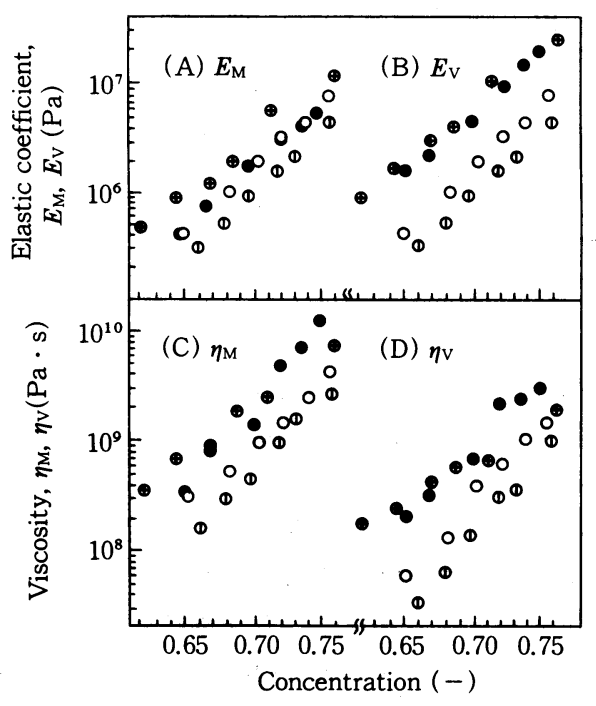

(A) $E_{\mathrm{M}},(\mathrm{B}) E_{\mathrm{V}}$, (C) $\eta_{\mathrm{M}}$ and (D) $\eta_{\mathrm{V}}$ Symbols : $\oplus$ CMC, $\bigcirc$ HPMC, $\ominus$ PVM, (1) PVA, without binder

Fig. 9 Coefficients of modified Burgers' model for kaolin HFS

Table 2 Coefficients in Eq. (2) for kaolin.

\begin{tabular}{c|c|c}
\hline & Without binder & With binder* $^{*}$ \\
\hline$\alpha_{\eta}$ & 10 & 10 \\
$\alpha_{\mathrm{E}}$ & 3 & 5 \\
$\theta_{\eta}$ & 800 & 800 \\
$\theta_{\mathrm{E}}$ & 40 & 300 \\
\hline
\end{tabular}

* Coeffcients were independent on the kind of binders 


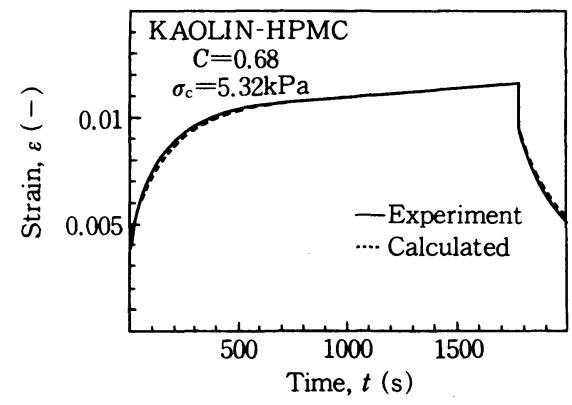

Fig. 10 Simulation of creep test of kaolin-HPMC HFS



(a) $C=0.73, \varepsilon_{\mathrm{M}}=0.0069(1 / \mathrm{s})(\mathrm{b}) 0.73,0.00038$

(c) $0.73,0.00017$ (d) $0.65,0.00057$

Fig. 11 Simulations of increasing strain test of kaolinHPMC HFS system ; arrow marks indicate the experimentally observed rapture stress

(HPMC添加は破断しない。のの減少がないなど) と を総合することによって結合剤の効果をほぼ十分にと らえることが出来る。

なお長時間クリープ(硬化あり)と, 定速度ひずみ増 加の実測例と計算結果をFigs. 10および11に示した。 簡単なモデルにもかかわらず実験結果をほぼ表現し ていることがわかる。更にFig. 11には試料の表現観
察によって推定した $\sigma_{\mathrm{R}}$ 値 $($ 前述)を示している。モデ 儿の適用範囲は $\sigma<\sigma_{\mathrm{R}}$ であるが, 計算曲線は破壞点のや や手前からずれ始めている。破壊点は可視化によって 推定したもので, 試料内では推定したよりもやや小さ い応力（及びひずみ）で微小破壊が始まっているであ ろう。したがって実測と計算とのずれは当をえたも のと考えられる。

\section{6. 結 論}

4 種類の七ラミックスに 5 種類の結合剤を組み合わ せて調整したHFSについて,一軸圧縮試験を行ない, 共通するHFSの粘弾性性質として,

（1）破壊時のひずみは材料, 結合剤の種類に関せず, $\varepsilon_{R}=0.1 \sim 0.2$ 範囲にある。これにたいして, 破壊強 度は材料, 結合剂の種類によって大幅に異なり, また 漕度依存性が大きい。

（2）破壞時の変形状態は結合剤の種類によって大き く異なる。HPMC添加は粘着性とある程度の流動性を 与えるので完全な破断を起こさない。CMC添加は脆 性がより大になり, HPC, PVM, PVAの順に流動性 が大になる。

（3）長時間叉は繰り返しクリープ試験では, ひずみ 硬化がみられた。これは応力を除くと, 長時間のうち に回復し（逆)チキソトロピーを示した。

（4）レオロジー的にはMexwell要素が主で, 応答の 滑らかさを表現し，かつ時間依存性を近似するには修 正 BurgersモデルEq.(3)がよい。モデルを適用して, 結合郕の影響を定量的に示した。

本報で示した試験方法は水系に限らず, 粒子・有機 バインダー系などのHFSにも適用できる。また得ら れたレオロジ一性質も一般のHFSに共通するところ が多いものと考えられる。

\section{Nomenclature}

$C$ : concentration of powder.

$E_{\mathrm{M}}$ : elastic coefficient of Maxwell's element

$E_{\mathrm{V}}$ : elastic coefficient of Voigt's element

$\alpha_{\mathrm{E}}:$ constant in Eq. (2)

$\alpha_{\eta}$ : constant in Eq. (2)

$\varepsilon_{M}$ : ratio of strain increase

$\varepsilon_{P}$ : permanent strain residue

$\varepsilon_{R} \quad$ : rupture strain

$\eta_{\mathrm{M}}$ : viscous coefficient of Maxwell's element

1) Scot Blair, C. W. : J. Rheol., 1, 127(1930)
(-) $\quad \eta_{\mathrm{V}}:$ viscous coefficient of Voigt's element

$(\mathrm{Pa} \cdot \mathrm{s})$

(Pa) $\quad \theta_{\mathrm{E}}:$ time constant in Eq. (2)

(Pa) $\quad \theta_{\eta}:$ time constant in Eq. (2)

$(-) \quad \sigma$ : stress

(-) $\sigma_{\mathrm{C}}:$ cnstant stress in creep test

$(1 / \mathrm{s}) \quad \sigma_{\mathrm{R}}:$ rupture stress

(-) $\quad \tau_{\mathrm{M}}: \eta_{\mathrm{M}} / \boldsymbol{E}_{\mathrm{M}}$

$(-) \quad \tau_{\mathrm{V}}: \eta_{\mathrm{V}} / E_{\mathrm{V}}$

\section{References}

2) Mooney, M. : J. Rheol., 2, 210(1931) 
3) Jsaterzebski, Z. D. : I\&EC Fundamentals, 6, 445 (1967)

4) Cheng, D. C. H. : Powder Technol., 37, 255(1984)

5) Yosimura, A., D. M. Kalyon and K. Prud'homme : J. Rheol., 32, 53(1988)

6) Yilmatzer, U. and D. Kalyon : J. Rheol., 33, 1197 (1989)

7) Mogami, T. : “Doshitsu Kogaku”, Gihodo(1967)

8) Yamaguchi, H. : Trans. Japan Soc. Civ. Engrs., No. 65(1959)

9) Nakamaru, H., Y. Sunada and Y. Nagase : $J$. Rheol., Japan, 22, 18(1994)

10) Nakamaru, H., M. Kuwai and Y. Nagase : $J$. Rheol., Japan, 22, 23(1994)

11) Murayama, S. and T. Shibata : Trans. Japan Soc. Civ. Engrs., 40, 1(1956), 74, 54(1961)

12) Sakurai, H. : Trans. Japan Soc. Civ. Engrs., 217. 65
(1973)

13) Sakurai, H. : J. Soc. Material Sci., Japan, 22, 1049 (1973)

14) Akai, K., N. Adachi and N. Ando : Trans. Japan Soc. Civ. Engrs., 225, 53(1974)

15) Nakamaru, H., T. Yuzuki and Y. Nagase : $J$. Rheol., Japan, 16, 66(1988)

16) Doshitsu kogakkai : “Doshitsu shikenho”, Doshitsu kogakkai(1979)

17) Shin-Etsu kagaku kogyo : "Metorozu"(1976)

18) Miyagawa, K. and A. Watanabe : Concrete J., Japan, 15, 119(1977)

19) Ogishi, S. : Concrete J., Japan, 12, 1(1974)

20) Jordaan, I. J., G. L. England and M. M. A. Khalifa : ASSE J. structual division, 103, 475(1977)

21) Suzuki, S. and M. Imaoka : J. Ceramic Ass., Japan, 88, 725(1980), 89, 252(1981), 90, 440(1982) 